\title{
Reminder interventions increased women's use of mammography and Pap smear screening
}

\author{
Somkin CP, Hiatt RA, Hurley LB, et al. The effect of patient and provider reminders on mammography and Papanicolaou smear \\ screening in a large health maintenance organization. Arch Intern Med 1997 Aug 11/25;157:1658-64.
}

\section{Objective}

To evaluate the effectiveness of reminder interventions for increasing women's use of mammography and Papanicolaou (Pap) smear screening.

\section{Design}

Randomised controlled trial with 6 month follow up.

\section{Setting}

3 medical centres from a large health maintenance organisation (Kaiser Permanente) in northern California, USA.

\section{Patients}

The mammography sample included 3513 women aged 50-74 years (mean age $60 \mathrm{y}$ ) who had not had a mammogram in the past 30 months, were continuously enrolled in the Kaiser Permanente Health Plan during that time, and lived in the area served by the medical centres. The Pap smear sample included 3564 women aged 20-64 years (mean age 47 y) who had not had a Pap smear in the past 36 months, were continuously enrolled in the Kaiser Permanente Health Plan during that time, and lived in the area served by the medical centres. 680 women were included in both samples.

\section{Intervention}

Women were allocated to receive a letter posted to their homes inviting them to make an appointment for a mammogram $(n=1171)$ or a Pap smear $(n=1188)$; to receive a letter plus have a reminder placed in their charts alerting providers of the need for a mammogram $(n=1171)$ or Pap smear $(n=1188)$; or to usual care for a mammogram (physician referral) $(n=1171)$ or a Pap smear $(\mathrm{n}=1188)$.

\section{Main outcome measures}

Data on patient receipt of a mammogram or Pap smear obtained from the Kaiser Permanente database of completed procedures.

\section{Main results}

More women who received letters had mammograms and Pap smears than women who received usual care (both $\mathrm{p}<0.001$ ) (table 1). More women who received letters plus chart reminders had mammograms and Pap smears than women who received letters only $(\mathrm{p}=0.02$ and $\mathrm{p}=0.04$, respectively) (table 2$)$. Heavier users of health plan services were more likely to be screened.

\section{Conclusion}

Women who received reminder letters were more likely to complete mammography and Papanicolaou smear screening than those who received usual care, and women who received reminder letters plus had reminders placed in their medical charts were more likely to complete mammography and Papanicolaou smear screening than those who received letters only.

Table 1 Letter v usual care*

\begin{tabular}{|c|c|c|c|c|c|}
\hline Outcome & $\begin{array}{l}\text { Letter } \\
\text { EER }\end{array}$ & $\begin{array}{l}\text { Usual } \\
\text { care } \\
\text { CER }\end{array}$ & $R B I(95 \% C I)$ & $\begin{array}{l}A B I \\
|E E R-C E R|\end{array}$ & $N N T(C I)$ \\
\hline $\begin{array}{l}\mathrm{Had} \\
\text { mammogram }\end{array}$ & $26.5 \%$ & $16.0 \%$ & $65.8 \%$ (41 to 95$)$ & $10.5 \%$ & 10 (7 to 14$)$ \\
\hline Had Pap smear & $19.4 \%$ & $9.1 \%$ & $113 \%$ (72 to 164$)$ & $10.3 \%$ & 10 (8 to 13$)$ \\
\hline
\end{tabular}

Table 2 Letter plus chart reminder v letter alone*

\begin{tabular}{|c|c|c|c|c|c|}
\hline Outcome & $\begin{array}{l}\text { Letter } \\
\text { and chart } \\
\text { reminder } \\
\text { EER }\end{array}$ & $\begin{array}{l}\text { Letter } \\
\text { alone } \\
\text { CER }\end{array}$ & $R B I(95 \% C I)$ & $\begin{array}{l}A B I \\
|E E R-C E R|\end{array}$ & $N N T(C I)$ \\
\hline $\begin{array}{l}\text { Had } \\
\text { mammo- } \\
\text { gram }\end{array}$ & $30.9 \%$ & $26.5 \%$ & $16.8 \%$ (3 to 33 ) & $4.4 \%$ & $23(12$ to 129$)$ \\
\hline $\begin{array}{l}\text { Had Pap } \\
\text { smear }\end{array}$ & $22.8 \%$ & $19.4 \%$ & $17.8 \%(0.8$ to 38$)$ & $3.4 \%$ & $29(15$ to 585$)$ \\
\hline
\end{tabular}

*Abbreviations defined in glossary; RBI, ABI, NNT, and CI calculated from data in article.

Source of funding: Innovation Program, Clinical Services Branch, The Permanente Medical Group, Oakland, California

For article reprint: C P Somkin, Division of Research, Kaiser Permanente Medical Care Program, 3505 Broadway, Oakland, CA 94611, USA. Fax +15104502071.

\section{Commentary}

Mammography and Pap smear screening are traditionally used in primary healthcare settings to identify women who may have breast or cervical cancer. However, many women do not receive the recommended screening for their age and risk status. ${ }^{1}$ This may occur because of provider or patient failure to initiate screening. The study by Somkin et al is particularly interesting because it focused on women who were overdue for screening.

This large randomised controlled trial on patient receipt of a mammogram or Pap smear included data from the medical centre's computerised database rather than from self report. The study does have some limitations: there is no record of whether study participants obtained screening outside of the health maintenance organisation; healthcare providers may have missed the chart reminder if they did not review the chart; sociodemographic data were not collected and therefore it is unclear if these results apply to all ethnic, socioeconomic, and educational backgrounds; and all letters were written in English rather than the woman's preferred language. The authors initially describe the health maintenance organisation as placing a "strong emphasis on the use of screening and other preventive health services". Further clarification is needed about what is included in "usual care" related to preventive screenings to assist the reader in understanding the difference in approach.

The findings are consistent with other studies which have shown that reminders, posted to the patient or placed in the medical chart, increase screening rates. ${ }^{2}$ Nurses must continue to be advocates for their patients in the areas of health promotion and disease prevention. One strategy would be to encourage the use of reminders for people who are overdue for their screening. While both strategies were effective, reminders placed in charts will only work for women who attend the primary care setting for other reasons, whereas all patients, especially those who are overdue, could be sent a letter written in their preferred language.

Marjorie A Maddox, CRNP, EdD Associate Professor of Nursing University of Scranton Scranton, PA, USA

1 Martin LM, Calle EE, Wingo PA, et al. Comparison of mammography and Pap test use from the 1987 and 1992 National Health Interview Surveys: are we closing the gaps? $\mathrm{Am}$ J Prev Med 1996;12:82-90.

2 McPhee SJ, Bird JA, Jenkins CN, et al. Promoting cancer screening: a randomized, controlled trial of three interventions. Arch Int Med 1989;149:1866-72 